\section{REVISTA Mario Alario JURIDICA D'Filippo}

\title{
La conciliación en conflictos con el estado como una herramienta para el desarrollo
}

\author{
Conciliation in conflicts with the state as a tool for development \\ Uriel Ángel Pérez Márquez ${ }^{1}$ \& Luis Fernando Reyes Ortega ${ }^{2}$ iD \\ Corporación Universitaria Rafael Núñez - Colombia
}

Para citaciones: Pérez Márquez, U., \& Reyes Ortega, L. (2021). La conciliación en conflictos con el estado como una herramienta para el desarrollo. Revista Jurídica Mario Alario D'Filippo, 13(26), 203-221.

https://doi.org/10.32997/2256-2796-vol.13num.26-2021-3621

Recibido: 27 de marzo de 2021

Aprobado: 10 de junio de 2021

Editor: Fernando Luna Salas. Universidad de Cartagena-Colombia.
Copyright: () 2021. Pérez Márquez, U., \& Reyes Ortega, L. Este es un artículo de acceso abierto, distribuido bajo los términos de la licencia

https://creativecommons.org/licenses/by-nc$\mathrm{sa} / 4.0 /$ la cual permite el uso sin restricciones, distribución y reproducción en cualquier medio, siempre y cuando que el original, el autor y la fuente sean acreditados.

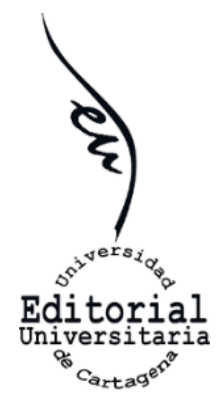

\section{RESUMEN}

Este trabajo de investigación tiene como objetivo principal Analizar la función de la Conciliación como herramienta para el Desarrollo, en el marco de los conflictos con el Estado; lo anterior, partiendo de que la conciliación, tal y como ha sido concebida, busca resolver o prevenir los conflictos sin necesidad de acudir al juez. Sin embargo, esta posibilidad es compleja tratándose de conflictos con entidades públicas, entre otras cosas, porque el Estado debe garantizar y proteger el orden público y el interés general, representados en el patrimonio público. Por esa razón se exige que los acuerdos que se pretendan celebrar sean revisados por un juez especializado. Sin embargo, este proceso resta eficacia a la figura ya que desnaturaliza la esencia autocompositiva de la conciliación y además porque este juez, el de lo contencioso administrativo, tiene en su ADN la función de asesorar al ejecutivo en sus actuaciones. Es imperativo un cambio en el procedimiento que posibilite la implementación de una verdadera cultura de paz, entendida ésta en el marco de los objetivos del desarrollo sostenible.

Palabras clave: Convivencia ciudadana; cooperación para le desarrollo; defensa del estado; cultura de paz; derechos ciudadanos.

\begin{abstract}
The main objective of this research work is to analyze the function of Conciliation as a tool for development, within the framework of conflicts with the State; The foregoing, based on the fact that conciliation, as it has been conceived, seeks to resolve or prevent conflicts without the need to go to the judge. However, this possibility is complex in the case of conflicts with public entities, among other things, because the State must guarantee and protect public order and the general interest, representing the public patrimony. For this reason, it is required that the agreements to be concluded be reviewed by a specialized judge. However, this process reduces the effectiveness of the figure since it denatures the self-compositional essence of the conciliation and also because this

\footnotetext{
1 Abogado litigante, conciliador en derecho y consultor especializado. Docente con experiencia en investigación (Corporación Universitaria Rafael Núñez, Universidad Tecnológica de Bolívar, Universidad de San Buenaventura Seccional Cartagena, UdC, Universidad del Magdalena, Universidad Libre, entre otras). Tutor temático de maestrías. Conjuez del Tribunal Administrativo de Bolívar. Conjuez del Consejo Seccional de la Judicatura de Bolívar. Especialista en Derecho Contencioso Administrativo (Universidad Externado de Colombia). Especialista en Contratación Estatal (Universidad de Medellín). Estudios de Maestría en Derecho Administrativo (Universidad Externado de Colombia). Magister en Contratación Estatal (universidad de Medellín). uriel.perez@ curnvirtual.edu.co

${ }^{2}$ Abogado. Conciliador en Derecho. Especialista en Derecho Procesal. Especialista en Contratación Estatal. Magíster en Derecho Procesal. Estudiante de Doctorado en Derecho Procesal Contemporáneo. Docente Universitario. luisreyesortega@hotmail.com
} 
judge, the administrative litigation judge, has in his DNA the function of advising the executive in his actions. A change in procedure is imperative that enables the implementation of a true culture of peace in this special category of conflicts.

Keywords: Citizen coexistence; cooperation for development; defense of the state; peace culture; citizen rights.

\section{INTRODUCCIÓN}

En Colombia, la conciliación tiene rango constitucional. El artículo 116 Superior, modificado por el artículo 1 del acto Legislación 03 de 2002, constituye el fundamento de los mecanismos alternativos de solución de conflictos en forma general y de la conciliación y el arbitraje en particular. Además, viene definida desde el artículo 64 de la Ley 446 de 1998 como un mecanismo de resolución de conflictos a través del cual dos o más personas gestionan por sí mismas la solución de sus diferencias, con la ayuda de un tercero neutral y calificado, denominado conciliador.

El texto constitucional le confiere al poder judicial la función de administrar justicia, pero esto no significa exclusividad en su ejercicio ni exclusión de otras autoridades o de los particulares. El artículo constitucional permite que los particulares sean investidos de forma transitoria de la función de administrar justicia en la calidad de conciliadores y de árbitros.

Sin embargo, esta figura admite algunas críticas, por ejemplo, las que se puedan hacer respecto a los conciliadores. En cuanto al arbitraje, es claro que este es un ejemplo de heterocomposición de los conflictos. El árbitro impone su decisión a las partes, actúa de forma transitoria como un juez y tiene similares facultades que este; pero el conciliador no, este facilita el acuerdo entre las partes, pero no decide, no les impone su decisión; no tiene este poder. La conciliación no tiene nada que ver con un método jurisdiccional tradicional para resolver los conflictos.

El conciliador no toma decisiones, a pesar de que el texto constitucional dispone que está facultado para administrar justicia. Suscribe el acta de conciliación que contiene el acuerdo al cual llegan las partes, pero esto no significa que el decide e impone los términos del acuerdo. Su firma da fe de su presencia y conducción de todo el procedimiento conciliatorio e incluso puede no estar de acuerdo con lo acordado por las partes. En este caso solo podrá dejar las constancias al respecto en el acta que contiene el acuerdo, pero no podrá jamás modificar el acuerdo logrado por las partes o imponerles su decisión.

Además, el conciliador no le pone fin al conflicto stricto sensu en derecho administrativo. El conflicto termina una vez aprobado el acuerdo por el juez de lo contencioso administrativo, lo que deviene en una verdadera dificultad, 
si se atiende a la finalidad que persigue el mecanismo de autocomposición, en la medida que se corre el riesgo de alejar - en la práctica- el acceso a la justicia de los particulares que se ven envueltos en un litigio con la administración; sin aprobación judicial el acuerdo conciliatorio no produce efectos jurídicos, no es vinculante para las partes.

La conciliación es un mecanismo de solución de los conflictos que permite ponerles fin, pero el conciliador no es un juez y él no decide. Incluso la Corte Constitucional ha considerado la conciliación como un mecanismo de solución asistido de los conflictos; es decir, el conciliador tiene una función de presentar propuestas de fórmulas de arreglo y un deber de colaboración con los intervinientes en una conciliación, pero no puede disponer del conflicto.

Además, si se atiende a la naturaleza del juez de lo contencioso administrativo, liderado por el Consejo de Estado como tribunal de cierre, quien originariamente era un órgano consultivo del poder ejecutivo, se pueden observar algunas dificultades en el proceso de homologación o aprobación de los acuerdos celebrados vía conciliación extrajudicial como requisito de procedibilidad.

Es precisamente en este contexto complejo, en el que además ya se está estudiando en el Congreso de la República un estatuto de la conciliación que propone unos importantes cambios en la materia que se estudia en este documento y considera oportuno revisar desde una visión crítica el funcionamiento de la conciliación en materia contencioso administrativa.

Se tiene entonces, como planteamiento inicial que la utilización de la conciliación extrajudicial como requisito de procedibilidad en materia contencioso administrativa, no se compadece con la naturaleza, fines y filosofía de la herramienta de autocomposición.

Para sustentar tal afirmación se procederá a realizar un ejercicio demostrativo que (i) describa brevemente las principales características de la figura, (ii) que evidencie la dificultad que reviste la exigencia de homologación por parte del juez, que además tiene una marcada vocación de salvaguarda de los intereses generales, representados en el actuar de la Administración y (iii) que describa la forma como debe ser concebido este mecanismo en materia administrativa de tal forma que contribuya a generar instituciones sólidas, desde lo propuesto en los objetivos del desarrollo sostenible.

\section{Método}

Las reflexiones aquí plasmadas provienen de una investigación cualitativa dado que utiliza la recolección de datos sin medición numérica (Sandoval, 2002) y su propósito es la reconstrucción de la "realidad" como fruto de un 
proceso histórico de construcción, vista de conformidad con la lógica y el sentir de sus protagonistas.

Además, se tiene que la Investigación es de la clase Jurídica. Dentro de esta clase, se ubica dentro del género de las teórico-Jurídicas (Briones, 2005).

La presente opinión tiene un método descriptivo y documental bibliográfico. Es descriptivo porque busca exponer los fundamentos teóricos y jurisprudenciales del control inmediato de legalidad. Es documental pues se realiza apoyándose en fuentes de carácter documental. Es del carácter especial de las bibliográficas pues su objeto de estudio está en la jurisprudencia, obras jurídicas de distinta índole, que recogen los supuestos y planteamientos respecto al control inmediato de legalidad de las decisiones adoptadas en el estado de emergencia económica, social y ecológica.

El método a partir del cual se realizará el presente documento también es el hermenéutico, entendido como la interpretación del texto, en la que la el intérprete se liga con la cosa transmitida, resinificándola a partir de su experiencia (Nina Ferrer, Juan Acosta, Donaldo Villegas, 2018). En consonancia con lo anterior, la técnica predominante será el análisis documental, haciendo también uso de matrices para triangulación hermenéutica de los resultados.

\section{Capítulo I. Particularidades estructurales de la figura.}

En Colombia, la conciliación en contencioso administrativo es un procedimiento reglado. De acuerdo con la ley, para que exista conciliación en el derecho administrativo se necesitan al menos dos partes: una debe ser una entidad pública o una persona pública, un conciliador que actúa como facilitador pero que no decide y un conflicto relacionado con un asunto de carácter particular y de contenido económico o patrimonial de conocimiento del juez administrativo. No existe entonces libertad absoluta al momento de utilizar la conciliación. Los asuntos que permiten utilizarla están determinados (Ley 1437, 2011), lo cual en principios facilita que se use; sin embargo, para ciertos asuntos o materias el tema admite discusión.

Tiene otras características que a nuestro juicio son más de forma, razón por la cual no haremos especial énfasis en ellas, tales como la necesidad de actuar mediante abogado, o ante el ministerio público; la regla de interrupción de la caducidad; la participación de los comités de conciliación; también se tiene que se puede agotar por una sola vez y, de las que más importa en este estudio, requiere ser aprobada por el juez de lo contencioso administrativo.

Ahora bien, el objeto de la conciliación no puede confundirse con la finalidad buscada. Una cosa es la intención de prevenir un daño, finalizando anticipadamente un conflicto o evitándolo y otra es el objeto, que debe 
considerarse respecto del acuerdo, que se encuentra donde están las prestaciones que se estudian, las cuales se relacionan con los aspectos patrimoniales o con la relación jurídica en negociación (Peláez, 2016).

En ese sentido se debe recordar que una entidad pública puede conciliar de forma total o parcial en los asuntos de carácter particular y de contenido económico o patrimonial. Se puede llegar a un arreglo amigable en los asuntos en los que es posible transigir, desistir y conciliar; esta es la regla general que debe aplicarse.

Un asunto será susceptible de transacción cuando involucre derechos o bienes patrimoniales sobre los cuales los titulares tienen capacidad de disposición, es decir, la conciliación es posible cuando los derechos en conflicto son de libre disposición por su titular y cuando existe libertad de renuncia. Es la capacidad de renuncia, de disposición, la que determina la posibilidad de transigir sobre un asunto sobre el cual se discute. La libertad de renuncia la define la naturaleza del derecho y le corresponde al legislador establecer en cuáles casos es posible; se requiere la capacidad legal de disposición. Entonces, frente a ciertos derechos o a ciertos bienes, el legislador puede establecer su disponibilidad ${ }^{3}$.

No sucede igual cuando se revisa el principio de la imposibilidad de conciliar en los asuntos en los que el legislador no permite su disposición. En principio, el legislador prohíbe la conciliación en asuntos de orden público y de interés general. El concepto de orden público se edifica a partir de una pluralidad de asuntos en los cuales el Estado y la sociedad tienen interés particular. Es posible incluir en dicho concepto los derechos personalísimos y los que tienen por finalidad la protección de las personas vulnerables en el plano social y el económico. Una norma se considera de orden público cuando regula la organización de una sociedad con el fin de garantizar su buen funcionamiento. (Díaz, 2006)

La noción de orden público aplicado al dominio administrativo trae consigo restricciones a la libertad de transigir y conciliar. De modo que se prohíbe derogar por la convención de los particulares las leyes que conciernen al orden público. Este es un obstáculo para que la Administración renuncie a ejercer las prerrogativas que le son propias en el marco del interés general y, además, es uno de los argumentos que defienden la intervención posterior del juez en la aprobación de la conciliación.

Frente a esta dificultad, el juez debe establecer si una norma es de orden público o si un derecho responde a esta condición cuando el legislador no le ha conferido de forma expresa tal calificación. Se consideran de orden público, por ejemplo, las normas que regulen el estado civil de las personas,

\footnotetext{
${ }^{3}$ De acuerdo con los artículos 2469 y siguientes del código civil, son susceptibles de transacción las cosas o los asuntos que por su naturaleza o contenido pueden negociarse, siempre que el acuerdo al cual lleguen las partes no atenta contra la ley, el orden público, la moral o las buenas costumbres.
} 
su capacidad, las normas de procedimiento y de competencias, los derechos fundamentales, los derechos e intereses colectivos, los derechos mínimos en materia laboral y los derechos frente a los cuales existe certeza en materia laboral (Peláez, 2016).

Es por esa ductilidad en el contenido y alcance de la noción de interés general que la conciliación con entidades estatales tiende a ser más compleja, con lo que a fin de cuentas se ve afectada la eficacia en su implementación.

\section{Capítulo 2. Aprobación de la conciliación ante un juez con alma de consultor}

En el derecho administrativo, el acuerdo alcanzado por las partes hay que agregarle la decisión del juez, llamada auto de aprobación, la cual le confiere validez, eficacia y efectos jurídicos al acuerdo conciliatorio, además de conferirle el sello de cosa juzgada y de prestar mérito ejecutivo. Cuando el juez administrativo estudia un acuerdo conciliatorio, se debe asegurar de que no sea lesivo al patrimonio público y no se encuentre viciado de nulidad absoluta; esto significa que el acto que contiene el acuerdo conciliatorio, en el caso de una conciliación extrajudicial, no produce efectos jurídicos sin la aprobación del juez administrativo. Lo mismo aplica para el acuerdo logrado en virtud de una conciliación judicial. La conciliación contenida en el acta de conciliación forma una unidad con la decisión del juez que aprueba el acuerdo conciliatorio y produce efectos jurídicos como una unidad. La conciliación sin su respectiva aprobación judicial es un acuerdo que no produce efectos jurídicos; la conciliación tendrá el efecto de cosa juzgada, con la aprobación del juez administrativo.

La fuerza principal de un mecanismo alternativo como la conciliación debe reposar en la voluntad de las partes y debe permitir ponerle fin al conflicto con plenos efectos sin la intervención de un juez. La existencia de una aprobación judicial generalizada de las conciliaciones en derecho administrativo no resulta del todo necesaria, a pesar de estar justificada; pero su ausencia exige la existencia de una cultura conciliatoria y de reformas normativas.

La existencia de un control generalizado sobre los acuerdos conciliatorios en el derecho administrativo no es coherente con el objeto de la conciliación, cuyo fin es evitar recurrir a los tribunales y permitir, con su uso, que las partes le pongan fin a su disputa, toda vez que la conciliación debe reposar sobre la autonomía de la voluntad de las partes.

La eficacia del acuerdo entre las partes depende de la decisión del juez, que finalmente decide si el acuerdo está acorde a la normatividad y le pone fin al conflicto. En realidad, las partes no tienen la facultad de finalizar el conflicto por ellas mismas; su acuerdo produce efectos jurídicos si es aprobado por el 
juez contencioso. La conciliación, en derecho administrativo, para surtir plenos efectos, exige el acta que contiene el acuerdo de las partes y la decisión del juez que lo aprueba.

Un mecanismo alternativo con tantas formalidades no es bueno; el formalismo no contribuye a su desarrollo y a su eficacia. La conciliación debe apoyarse más en la flexibilidad y en la voluntad de las partes de ponerle fin al conflicto, sin que esto signifique que se acepten comportamientos arbitrarios o contrarios a la normatividad vigente. La voluntad de desarrollar los mecanismos alternativos de solución de conflictos como la conciliación extrajudicial o la transacción, se origina en la prevención de lo contencioso, de evitar un proceso judicial y de permitirle a las partes apropiarse del conflicto y ponerle fin ellas mismas.

Los argumentos de la defensa del interés general o el orden púbico no son lo suficientemente contundentes como para justificar la existencia de un mandato legal de aprobación judicial generalizado de las conciliaciones en derecho administrativo, teniendo en cuenta que en su concepción general la conciliación es un mecanismo alternativo para resolver conflictos, sin que sea necesario acudir al juez, y el acto que contiene el acuerdo conciliatorio permite su ejecución por la mera voluntad de las partes manifestada en el acuerdo conciliatorio como sucede en materia privada y sucedería en derecho administrativo si el requisito de aprobación judicial desapareciere.

Al respecto ha dicho la Corte Constitucional en sentencia C- 163 de 1999:

La garantía constitucional de acceso a la justicia no significa que todas las disputas entre los particulares deban ser resueltas por los jueces, pues precisamente el artículo 116 de la Carta garantiza la existencia de mecanismos alternativos de solución de conflictos, como la conciliación o el arbitraje, los cuales pueden ser ampliados por el legislador [...]. Los mecanismos alternativos de resolución de conflictos encuentran base constitucional no solo en su reconocimiento expreso en el artículo 116 superior, sino también en otros principios y valores constitucionales. Así, su presencia puede constituir una vía útil, en ciertos casos, para descongestionar la administración de justicia formal, con lo cual se potencia la eficacia, celeridad y efectividad de la justicia [...] (Corte Constitucional, 1999).

Además, un mecanismo alternativo como la conciliación permite desarrollar la democracia y el principio de participación, ya que al utilizarla los particulares se convierten en colaboradores de la justicia puesto que participan en la resolución de sus conflictos.

La existencia de una decisión judicial no es la única forma de acceder a la justicia; un mecanismo alternativo como la conciliación permite ponerle fin a un conflicto por decisión de las partes. En Colombia, el control judicial de los acuerdos conciliatorios existe, en principio, para garantizar la legalidad de los 
acuerdos y proteger el patrimonio público; en otras palabras: se parte de la idea de que la conciliación pueda representar una amenaza para el patrimonio público.

El control que se le confiere al juez administrativo constituye un medio eficaz para garantizar el principio de legalidad de la administración y contribuye, en principio, en el respeto de la ley en sus diferentes actuaciones. La decisión tomada por el juez encuentra su fundamento en el análisis de la conducta de la administración, de sus funcionarios o representantes para determinar su conformidad con el orden jurídico. En términos de Marienhoff, la administración actúa secundun legem, puesto que la actividad estatal es sublegal, lo cual tiene plena aplicación en Colombia (Consejo de Estado, 2005).

La exigencia legal de la aprobación del acuerdo conciliatorio se justifica puesto que, con la utilización de la conciliación, el patrimonio público y los intereses de la colectividad están comprometidos. El control confiado al juez administrativo opera para favorecer a la administración, el juez debe examinar por completo el contenido del acuerdo para determinar su legalidad y la existencia de prueba suficientes para asegurar la existencia de la obligación reconocida, lo que permite considerar una gran probabilidad de condena en contra del Estado en caso de un proceso judicial. Las justificaciones de la existencia del control judicial son claras, pero la existencia del requisito de aprobación judicial no va de la mano con el objetivo de mecanismos alternativos de resolución de conflictos como la conciliación.

Al lado de estas razones no se puede soslayar el hecho de que este tránsito obligatorio por los predios de la judicatura -relativamente justificado según lo hemos expresado en líneas precedentes- definitivamente resta efectividad y eficacia a la conciliación. No sólo por extender la posibilidad de ver el acuerdo materializado, sino porque este juez de lo contencioso administrativo, tiene una tendencia natural a proteger el orden público según sea entendido por la Administración. En otras palabras, el juez que debe ser imparcial, en materia contencioso administrativa tiende a proteger lo intereses del Estado y esto obedece a su origen principalmente consultivo.

Colombia cuenta desde el siglo XIX con un Consejo de Estado y, desde principios del $\mathrm{XX}$, con una jurisdicción de lo contencioso administrativo de inspiración indiscutiblemente francesa, lo que no significa identidad exacta. Esta jurisdicción ha contribuido también a la creación y a la consolidación de un derecho administrativo en Colombia aunque éste, a diferencia del francés, sea mayoritariamente legislado.

Es inevitable acudir a la fuente francesa del Consejo de Estado, órgano de origen remoto, incluso medieval si nos atenemos a la investigación del 
profesor Ospina (2009), que se llamaba Consejo del Rey, que era una entidad asesora o asistencial del monarca en la cotidianidad del ejercicio del poder y que poco a poco fue adoptando funciones jurisdiccionales, mismas que se evidenciaron con mayor claridad luego de la Revolución de 1789.

En Colombia, desde 1991, existe una jurisdicción de lo contencioso administrativo- como tal- compuesta en primera instancia por los Jueces Administrativos (jueces individuales), previstos por la Ley 446 de 1998 y los Tribunales Administrativos y, en la cabeza de la jurisdicción, el Consejo de estado. Debe resaltarse que, a diferencia del sistema francés, el Consejo de Estado colombiano ha hecho un esfuerzo por ejercer una influencia administrativa menor.

En efecto, la jurisdicción de lo contencioso administrativo y la carrera judicial en Colombia son administradas, como sucede respecto de cualquier otra jurisdicción, por el Consejo Superior de la Judicatura, órgano independiente que garantiza la independencia y el auto gobierno de la Rama Judicial del poder público.

Sin embargo, la función consultiva, que hace parte el Consejo de Estado, es un elemento fundamental heredado del diseño administrativo francés. No debe olvidarse que la jurisdicción administrativa francesa pertenece a la administración misma y no al inexistente poder jurisdiccional, como resultado de un proceso histórico, "racionalizado" a través de la ficción juzgar a la administración aún es administrar. Este hecho, sumado a ciertos problemas de separación entre la administración y el juez administrativo, nos lleva a afirmar que el adjetivo "administrativa" no habla solamente del campo de competencias que determina la especialidad de la jurisdicción, sino también de los orígenes administrativos de este juez y de las huellas que está génesis ha marcado en su organización y funcionamiento: la jurisdicción administrativa administra (Ospina, p. 28).

Recientemente se realizó una reforma al articulado de la Ley 1437 de 2011 (Código Administrativo y de lo Contencioso Administrativo), mediante la Ley 2080 de 2021, en la cual a grandes rasgos no se contemplan cambios en la forma como se concibe y se desarrolla la conciliación en materia administrativa, en el sentido que se limita a hacer reformas frente a la competencia para conocer la ejecución de las condenas hechas mediante conciliación extrajudicial o judicial, el momento en el cual dentro del proceso se pueden llevar a cabo conciliaciones, sobre qué aspectos, frente a la competencia para presentar apelaciones contra las aprobaciones de conciliaciones, entre otras, no obstante, mantiene el requisito de aprobación por parte del juez administrativo, de lo acordado en la conciliación para que hagan tránsito a cosa juzgada. Con la reforma no se presenta ningún avance en cuanto a una concepción de la conciliación más acorde al significado y a la funcionalidad con la que fue estructurado y contemplado este mecanismo. 


\section{Capítulo 3. La Conciliación en materia Administrativa a la luz de los ODS}

El acceso a la administración de justicia como derecho que debe ser garantizado en todos los ámbitos sociales, se convierte en uno de los puntos fundamentales abordados y desarrollados en el Objetivo de Desarrollo Sostenible (ODS) $\mathrm{N}^{\circ} 16$, el cual contempla dentro de los ítems que lo componen y sobre el cual se basa su ruta de trabajo, el acceso a la justicia, en esa medida se considera, de un lado que "Los derechos de acceso otorgan legitimidad a la toma de decisiones y contribuyen a lograr paz y seguridad y a prevenir los conflictos," y por otro que "El estado de derecho es un catalizador del desarrollo sostenible, siendo el acceso a la justicia determinante para la justiciabilidad y exigibilidad de los derechos humanos".

A partir de ello, y teniendo en cuenta que el acceso a la justicia no implica solo acudir a la jurisdicción o accionar el aparato judicial, sino que el acceso a la justicia también se puede hacer efectivo con la utilización de los mecanismos alternativos para resolver los conflictos, dentro de los cuales se encuentra la Conciliación, que en ocasiones se convierte en un requisito de procedibilidad para poder acceder a la administración de justicia tradicional, pero que su principal objetivo es permitir llegar a acuerdos amigables entre las partes, sin necesidad de iniciar procesos judiciales.

Tratándose de la conciliación en materia administrativa, los acuerdos a los que se llegue en las mismas, por encontrarse en juego recursos públicos e intereses generales, deben ser sometidos a un control o aprobación por parte del juez administrativo, tal y como lo contempla el artículo 12 de Decreto 1706 de 2009 y que luego fue compilado en el Decreto 1069 de 2015 en el artículo 2.2.4.3.1.1.12., "El agente del Ministerio Público remitirá, dentro de los tres (3) días siguientes a la celebración de la correspondiente audiencia, el acta de conciliación, junto con el respectivo expediente al juez o corporación competente para su aprobación".

Si se tiene en cuenta que la naturaleza de la conciliación como mecanismo alternativo, busca principalmente que las controversias se resuelvan a través de la autocomposición y un arreglo entre las partes enmarcado dentro de los postulados legales de manera ágil, sin que ello implique llegar a al órgano jurisdiccional, el requisito adicional que se exige de la aprobación del acuerdo por parte del juez administrativo, no guarda relación con la recomendación que desde el ODS 16, se recomienda a los Estados a fin de poder alcanzar el mismo, en la medida que una de las acciones que se deben implementar para poder avanzar en la implementación de este objetivo, se hace "necesario desarrollar mecanismos de gobierno abierto y establecer mecanismos de agilización de trámites y procedimientos administrativos" (CEPAL, ODS 
16), en la medida que es un trámite adicional que alguna forma retrasa los procedimientos.

En razón a ello, se hace necesario que se replantee el procedimiento establecido para el desarrollo de la conciliación en materia administrativa, sin que ello implique flexibilizar la exigencia de los que los acuerdos deben realizarse dentro del marco legal y en cumplimiento de las normas que regulan cada caso, sino que por el contrario, se utilice al Ministerio Publico como veedor de que el acuerdo se lleve a cabo dentro del margen de la legalidad, a fin de salvaguardar con ello los recursos públicos y el interés general, así como facilitar la justiciabilidad de los derechos de una forma más eficiente.

Esto conlleva además, a que el Estado tenga unas instituciones mucho más sólidas, que permitan que se cuente con mecanismos que lleven a la solución de los conflictos, que no impliquen acudir ante el juez, si no que se puedan resolver entre Estado y particulares en uso de la autocomposición en el marco de la legalidad, eliminando requisitos formales adicionales y que puedan aumentar la competitividad del Estado frente a la respuesta que se pueda dar ante los conflictos que se presenten, y frente a inversionistas que quieran establecer relaciones de cooperación con el Estado en el avance en objetivos de desarrollo económico y social, al encontrar mecanismos que les permitan resolver controversias de forma ágil, efectiva y en salvaguarda de los intereses de ambas partes.

\section{Análisis}

La figura de la conciliación es conocida de vieja data en la normatividad colombiana, inclusive antes de la entrada en vigencia de la constitución de 1991; este mecanismo alternativo de solución de conflictos en asuntos contencioso administrativo en Colombia se materializa con la promulgación de la ley 23 de 1991, norma que consagraba la posibilidad facultativa de acudir a la conciliación, en sede judicial o extrajudicial, siempre que se tratase de un conflicto de carácter particular y de contenido patrimonial y que tuviere que resolverse en la jurisdicción contenciosa administrativa. De hecho, es copioso el desarrollo jurisprudencial que desde la Corte Constitucional ha tenido la fiura aquí analizada.

La citada norma definió el procedimiento que se debía adelantar ante el Agente del Ministerio Público y su respectiva aprobación judicial; precisó la suspensión de los términos de la vía gubernativa y de la caducidad de la acción; le otorgó al acta contentiva del acuerdo la consecuencia de suplir el consentimiento expreso y escrito del titular de acto administrativo de carácter particular, cuando como consecuencia del arreglo fuese necesaria su revocatoria; determinó las sanciones aplicables tanto a los funcionarios públicos como a los particulares, en caso de inasistencia a la audiencia de 
conciliación, renuencia a proponer fórmulas de arreglo o rechazo de las posibilidades de acuerdo legítimo. Estos aspectos procedimentales son aborados por pluralidad de autores, entre los que se encuentran el profesor Junco (2007), el doctrinante García (2008), el maestro Henao (1996) y el hoy procurador delegado Gómez Lee (2014).

Se ha sostenido que la conciliación como mecanismo de solución de conflictos es de importancia para "(i) hacer efectivo uno de los fines constitucionales como el de la convivencia pacífica; (ii) permite la participación directa de los interesados en la resolución de us conflictos; (iii) son otra forma de hacer efectivo el derecho de acceso a la administración de justicia, y (iv) son un buen mecanismo para lograr la descongestión judicial. (Corte Constitucional, 2013).

La Corte Constitucional explicando la naturaleza de la conciliación ha dicho que esta en estricto sentido no tiene el carácter de actividad jurisdiccional, porque el conciliador, autoridad administrativa o judicial, o particular, no intervinienen para imponer a las partes la solución del conflicto en virtud de una decisión autónoma e innovadora (Corte Constitucional, 1999).

Lo anterior nos lleva a coincidir con la reiterada doctrina constitucional que pregona las bondades de esta figura de autocomposición que patentiza la realización de una cultura de paz y de desarrollo sostenible.

\section{Conclusiones}

En Colombia ha existido y existe todo un movimiento para hacer de la conciliación en el derecho administrativo un mecanismo eficaz. Sin embargo, su eficacia es cuestionable. La conciliación se ha convertido en un mecanismo bastante regulado, a veces mal entendido y falto de flexibilidad. Los vacíos jurídicos persisten, y aunque existe un objeto de la conciliación limitado por la ley, los cuestionamientos subsisten, como se explicó en la primera parte de esta obra. En 1995, por ejemplo, la conciliación se utilizó de manera efectiva para resolver disputas relacionadas con asuntos propios de las relaciones contractuales que no habían sido legalmente celebradas por la falta de una partida presupuestal o de un documento contractual que soportara el servicio prestado. En otras palabras: se utilizó para reconocer y regular hechos cumplidos. En esa época fue bien recibido dicho análisis, pero con el tiempo los hechos cumplidos que debían ser la excepción se convirtieron en la regla y la conciliación se utilizó para evadir las normas de orden público aplicables a la actividad contractual del estado y para desviar dineros de la administración, lo cual término afectándola por ser usada como medio para defraudar las arcas del estado.

El problema no proviene de los mecanismos alternativos de solución de conflictos, sino de factores externos al mecanismo como, por ejemplo, la 
corrupción, puesto que la conciliación se ha utilizado para cometer fraudes al Estado, es decir, para menoscabar el patrimonio público. En el derecho administrativo colombiano, la conciliación ha sido afectada, y continúa siéndolo, por factores externos al procedimiento mismo y por las particularidades colombianas. Esto ha generado una desconfianza alrededor del mecanismo y de su uso y ha justificado la existencia de un control judicial de los acuerdos conciliatorios en derecho administrativo. Sin embargo, se considera una exigencia innecesaria que resulta excesiva. Es una exigencia colombiana que obedece a las particularidades del país.

Ahora bien, aunque se debía propender a la flexibilización del procedimiento de la conciliación, está se convirtió, por el contrario, en un asunto extremadamente reglado, sin olvidar que el mecanismo no es bien entendido por quienes intervienen. La ley 1285 de 2009 y el Decreto 1716 de 2009 centran la eficacia de la conciliación en la tarea que realizan los comités de defensa judicial y de conciliación de las entidades públicas. Pero como se explicó, estos siguen sin garantizar un funcionamiento acorde con las necesidades de uso de la conciliación. Un análisis jurídico serio del origen de la conclusión, para cada asunto sometido a su consideración, debe ser efectuado por los comités, y será necesario superar las fórmulas de arreglo utilizadas por ellos hasta hoy, sin dejar de lado la importancia del conciliador, que debe desempeñar un papel activo en el desarrollo de la audiencia de conciliación, proponer fórmulas de arreglo y alentar a los miembros del comité de defensa judicial y de conciliación a conciliar y a reconsiderar su decisión con el fin de lograr un acuerdo justo para las partes. Los intervinientes no han comprendido la función ni el propósito del mecanismo, a pesar de que la conciliación le permite a las partes llegar a un acuerdo de forma más rápida y ahorrar dinero.

Finalmente, todas estas voces han tenido eco al interior del Gobierno y es por eso, que el 20 de julio de 2020 se radicó ante el Congreso de Colombia un proyecto de ley para crear el estatuto de la conciliación. En materia Contencioso administrativa trae estas propuestas:

Artículo 82. Definición de la conciliación extrajudicial en asuntos de lo contencioso administrativo. La conciliación extrajudicial en asuntos contencioso administrativos es un mecanismo alternativo de resolución de conflictos, a través del cual las partes de un conflicto que pueda ser conocido por la Jurisdicción de lo Contencioso Administrativo, gestionan por sí mismas la solución de sus diferencias conciliables, con la colaboración de un conciliador, neutral y calificado, que podrá ser un agente del Ministerio Público o un conciliador en derecho inscrito en un centro de conciliación autorizado por el Ministerio de Justicia y del Derecho.

La conciliación refrendada podrá ser objeto del recurso judicial de revisión y de control fiscal concomitante y preventivo 
Artículo 109. Refrendación del acuerdo. Los acuerdos conciliatorios en asuntos de lo contencioso administrativo serán refrendados por los agentes del Ministerio Público, siempre y cuando cumplan con los requisitos previstos en esta ley.

El acta en la que conste el acuerdo conciliatorio, junto con el acto de refrendación del Ministerio Público en firme, hace tránsito a cosa juzgada y prestará mérito ejecutivo.

Artículo 113. Recurso de revisión. Contra el acuerdo celebrado entre las partes y refrendado por el Ministerio Público procederá un recurso de revisión ante la Jurisdicción de lo Contencioso Administrativo, el cual conocerá el juez o corporación que fuere competente para dar trámite al medio de control correspondiente.

El recurso de revisión deberá ser interpuesto dentro de los cinco (5) días siguientes a la publicación y comunicación del acuerdo refrendado, vencidos los cuales el acuerdo y la refrendación quedarán en firme.

Una vez interpuesto el recurso, el agente del Ministerio Público remitirá el expediente dentro de los tres (3) días siguientes a la autoridad judicial competente.

La autoridad judicial improbará el acuerdo conciliatorio y la respectiva refrendación cuando encuentre demostrada alguna de las causales para su procedencia reguladas en esta ley.

El auto que decida la revisión será susceptible del recurso de apelación.

El auto que impruebe el acuerdo conciliatorio y la respectiva refrendación constituirá prueba del agotamiento del requisito de procedibilidad.

La interposición del recurso de revisión suspenderá los efectos del acuerdo conciliatorio mientras este se decide.

Se evidencia que definitivamente el objetivo es obviar la figura de la aprobación por parte del juez, y que sea un tercero, llámese Ministerio Publico o Conciliador como medio de control, quien realice la ratificación o no del acuerdo al que se llegue en sede de conciliación, previa verificación de cumplimiento de las normas que regulen cada caso; aunque queda abierta la posibilidad de acudir al clásico control de legalidad del acuerdo mediante un mecanismo expedito, en la medida que se puede someter a revisión dentro del término establecido para ello, so pena de quedar en firme lo allí acordado.

También se observa que se busca revivir la discusión sobre la posibilidad de abrir el abanico de posibilidades a los conciliadores competentes para conocer sobre los conflictos que surjan con la Administración. 
De la ley que finalmente se promulgue se podrá patentizar el grado de madurez o evolución que se haya adquirido como sociedad de cara a la construcción de una cultura de paz, a través de los mecanismos de autocomposición, independientemente de que una de las partes sea una entidad pública.

De igual forma con la Ley que pueda resultar de este proyecto, y que actualmente se encuentra pendiente para discutir ponencia en primer debate en el Senado de la Republica, se podría alcanzar una mayor competitividad del Estado frente a la solución de algunos de los conflictos que se originen en el desarrollo de la actividad administrativa, en la medida que se puede llegar a acuerdos más agiles en el margen de los postulados legales y reglamentarios, que lleven a finalizar controversias sin la necesidad de acudir a los medios judiciales ordinarios, conservando así la naturaleza de la conciliación como mecanismo alternativo para dirimir conflictos.

\section{Referencias}

Briones, G. (2005). Metodología de la Investigación en las Ciencias Sociales y en el Derecho. Santiago de Chile: Estudios de Opinion.

Constitución Política de Colombia. (1991). https://www.constitucioncolombia.com

Consejo de Estado. Sentencia No. 25000-23-26-000-2002-01216-01. [M.P. R Correa Palacio del 16 de marzo de 2005]. https://consejo-estado.vlex.com.co/vid/$\underline{52528613}$

Corte Constitucional. Sentencia C- 163 de 1999. [M.P. Alejandro Martínez Caballero del 17 de marzo de 1999]. https://www.corteconstitucional.gov.co/relatoria/1999/C-163-99.htm

Corte Constitucional. Sentencia C- 702 de 1999. [M.P. Fabio Morón Díaz del 20 de septiembre de 1999] https://www.corteconstitucional.gov.co/relatoria/1999/C$\underline{702-99 . h t m}$

Corte Constitucional. Sentencia C - 111 de 1999. [M.P. Alfredo Beltrán del 24 de febrero de 1999]. https://www.corteconstitucional.gov.co/relatoria/1999/C-11199.htm

Corte Constitucional. Sentencia C-165de 1993. [M.P. Carlos Gaviria del 29 de abril de 1993]. https://www.corteconstitucional.gov.co/relatoria/1993/C-165-93.htm

Corte Constitucional. Sentencia T-231 de 1994. [M.P. Eduardo Cifuentes del 13 de mayo de 1994 https://www.corteconstitucional.gov.co/relatoria/1994/t-23194.htm

Corte Constitucional. Sentencia C-414 de 1994. [M.P. Antonio Barrera del 22 de septiembre de 1994]. https://www.corteconstitucional.gov.co/relatoria/1994/C414-94.htm 
Corte Constitucional. Sentencia C-037 de 1996. M.P. Vladimiro Naranjo Meza del 5 de febrero de 1996]. https://www.corteconstitucional.gov.co/relatoria/1996/C037-96.htm

Corte Constitucional. (1996, 26 de septiembre). Sentencia C-489 (Antonio Barrera). https://www.corteconstitucional.gov.co/relatoria/1996/C-489-96.htm

Corte Constitucional. Sentencia C-617 de 1996. [M.P José Gregorio Hernández del 13 de noviembre de 1996]. https://www.corteconstitucional.gov.co/relatoria/1996/C-617-96.htm

Corte Constitucional. (Sentencia C- 215 de 2015. [M.P. Martha Sáchica del 14 de abril de 2015]. https://www.corteconstitucional.gov.co/relatoria/1999/C-21599.htm

Corte Constitucional. Sentencia C- 923 de 1999. [M.P. Álvaro Tafur Galvis del 18 de noviembre de 1999]. https://www.corteconstitucional.gov.co/relatoria/1999/C923-99.htm

Corte Constitucional. Sentencia C- 1436 de 2000. [M.P. Alfredo Beltrán del 25 de octubre de 2000]. https://www.corteconstitucional.gov.co/relatoria/2000/C-143600.htm

Corte Constitucional. Sentencia SU-1184 de 2001. [M.P. Eduardo Montealegre del 13 de noviembre de 2001]. https://www.corteconstitucional.gov.co/relatoria/2001/SU1184-01.htm

Corte Constitucional. Sentencia C-619 de 2001. [M.P. Marco Monroy Cabra del 14 de junio de 2001]. https://www.corteconstitucional.gov.co/relatoria/2001/c-61901.htm

Corte Constitucional. Sentencia C-831 de 2001. [M.P. Rodrigo Escobar Gil del 8 de agosto de 2001]. https://www.corteconstitucional.gov.co/relatoria/2001/c-831$\underline{01 . h t m}$

Corte Constitucional. Sentencia C-893 de 2001. [M.P. Clara Inés Vargas del 22 de agosto de 2001]. https://www.corteconstitucional.gov.co/relatoria/2001/c-893$\underline{01 . h t m}$

Corte Constitucional. Sentencia C-1195 de 2001. [M.P. Marco Monroy Cabra del 15 de noviembre de 2001]. https://www.corteconstitucional.gov.co/relatoria/2001/c1195-01.htm

Corte Constitucional. Sentencia C-285 de 2002. [M.P. Jaime Córdoba Triviño del 23 de abril de 2002]. https://www.corteconstitucional.gov.co/relatoria/2002/C-285$\underline{02 . h t m}$

Corte Constitucional. Sentencia SU-159 de 2002. [M.P. Manuel José Cepeda del 6 de marzo de 2002]. https://www.corteconstitucional.gov.co/relatoria/2002/SU159-02.htm 
Corte Constitucional. Sentencia T- 774 de 2004. [M.P. Manuel José Cepeda 13 de agosto de 2004]. https://www.corteconstitucional.gov.co/RELATORIA/2004/T774-04.htm

Corte Constitucional. Sentencia C-033 de 2005. [M.P. Álvaro Tafur Galvis del 25 de enero de 2005]. https://www.corteconstitucional.gov.co/relatoria/2005/c-03305.htm

Corte Constitucional. Sentencia T- 068 de 2005. [M.P. Rodrigo Escobar Gil del 28 de enero de 2005]. https://www.corteconstitucional.gov.co/relatoria/2005/T-068$\underline{05 . h t m}$

Corte Constitucional. Sentencia T-481 de 2005. M.P. Jaime Araujo del 8 de abril de 2005]. https://www.corteconstitucional.gov.co/relatoria/2005/T-481-05.htm

Corte Constitucional. Sentencia C-338 de 2006. [M.P. Clara Inés Vargas del 6 de mayo de 2006]. https://www.corteconstitucional.gov.co/relatoria/2006/c-33806.htm

Corte Constitucional. Sentencia T- 267 de 2009. [M.P. Humberto Sierra Porto del 3 de abril de 2009]. https://www.corteconstitucional.gov.co/relatoria/2009/t-26709.htm

Corte Constitucional. Sentencia T-715 de 2009. [M.P. Gabriel Mendoza del 10 de octubre de 2009]. https://www.corteconstitucional.gov.co/relatoria/2009/T-71509.htm

Corte Constitucional. Sentencia C- 222 de 2013. [M.P. María Victoria Calle del 17 de abril de 2013]. https://www.corteconstitucional.gov.co/relatoria/2013/c-22213.htm.

Corte Constitucional. Sentencia C- 160 de 1999. [M.P. Antonio Barrera Carbonell del 17 de marzo de https://www.corteconstitucional.gov.co/relatoria/1999/C-160-99.htm

Congreso de la república. (1991, 21 de marzo). Ley 23. Por medio de la cual se crean mecanismos para descongestionar los Despachos Judiciales, y se dictan otras disposiciones.

https://www.funcionpublica.gov.co/eva/gestornormativo/norma.php?i=6546

Congreso de la república. (2009, 22 de enero). Ley 1285. Por medio de la cual se reforma la Ley 270 de 1996 Estatutaria de la Administración de Justicia. http://www.secretariasenado.gov.co/senado/basedoc/ley_1285_2009.html

Congreso de la república de Colombia. (1998, 07 de julio). Ley 446. Por la cual se adoptan como legislación permanente algunas normas del Decreto 2651 de 1991, se modifican algunas del Código de Procedimiento Civil, se derogan otras de la Ley 23 de 1991 y del Decreto 2279 de 1989, se modifican y expiden normas del Código Contencioso Administrativo y se dictan otras disposiciones sobre descongestión, eficiencia y acceso a la justicia. http://www.secretariasenado.gov.co/senado/basedoc/ley_0446_1998.html 
Congreso de la república. (2001, 05 de enero). Ley 640. Por la cual se modifican normas relativas a la conciliación y se dictan otras disposiciones. http://www.secretariasenado.gov.co/senado/basedoc/ley 0640 2001.html

Congreso de la república. (2011, 18 de enero). Ley 1437 de 2011. Por la cual se expide el Código de Procedimiento Administrativo y de lo Contencioso Administrativo.

http://www.secretariasenado.gov.co/senado/basedoc/ley_1437_2011.html

Congreso de la república. (2021, 21 de enero). Ley 2080 de 2021. Por medio de la cual se reforma el Código de Procedimiento Administrativo y de lo Contencioso Administrativo -Ley 1437 de 2011- y se dictan otras disposiciones en materia de descongestión en los procesos que se tramitan ante la jurisdicción. http://sisjur.bogotajuridica.gov.co/sisjur/normas/Norma1.jsp?i=105225

Díaz, H. (2006). La conciliación judicial y extrajudicial: Su aplicación en el derecho colombiano. Bogota. Legis.

García, F. (2004). La conciliación en Derecho Administrativo. Bogotá. Universidad Externado de Colombia.

Gómez, I. (2014). Responsabilidad fiscal y gerencia de recursos públicos. Bogotá. Legis.

Henao, J. (1996). La conciliación en derecho administrativo. Bogotá. Ministerio de justicia y del derecho.

Junco, José R. (2007). La Conciliación, aspectos sustanciales y procesales. $4^{\mathrm{a}}$ ed. Bogotá.

Nina Ferrer, Juan Acosta, Donaldo Villegas. (2018). Metodología de la Invetsigación jurídica y socio-jurídica. Cartagena, Bolívar, Colombia: Bonaventuriana

Ospina, A (2009). De la jurisdicción administrativa a la jurisdicción contencioso administrativa: ¿Un viaje de ida y vuelta?. Bogotá: Universidad Externado.

Peláez, V (2016). La conciliación en el derecho administrativo colombiano. Bogotá: Universidad Externado.

Proyecto de ley "Estatuto de la Conciliación" (2020). Por medio de la cual se expide el Estatuto de Conciliación y se dictan otras disposiciones. http://leyes.senado.gov.co/proyectos/images/documentos/Textos\%20Radicados/ proyectos\%20de\%20ley/2020\%20-\%202021/PL\%2006620\%20Estatuto\%20de\%20la\%20Conciliacion.pdf

Presidencia de la república. (2009, 14 de mayo). Decreto 1716. Por el cual se reglamenta el artículo $\underline{13}$ de la Ley 1285 de 2009, el artículo $\underline{75}$ de la Ley 446 de 1998 y del Capítulo $\underline{V}$ de la Ley 640 de 2001. https://www.alcaldiabogota.gov.co/sisjur/normas/Norma1.jsp?i=36199 
Presidencia de la república. (2015, 26 de mayo). Decreto 1069. Por medio del cual se expide el Decreto Único Reglamentario del Sector Justicia y del Derecho.

Comisión Economica para America Latina y el Caribe (CEPAL). (s.f). Objetivos de Desarrollo Sostenible ODS 16. Paz, Justicia e Instituciones Solidas. https://www.un.org/sustainabledevelopment/es/objetivos-de-desarrollosostenible/

Sandoval, C. (2002). Investigacion Cualitativa. Bogota: Instituto Colombiano para el fomento de la educacion superior (ICFES).

Saza Pineda, J. F., \& Luna Salas, F. (2020). Vicisitudes del proceso monitorio en Colombia. Revista Jurídica Mario Alario D’Filippo, 12(24), 302-322. https://doi.org/10.32997/2256-2796-vol.12-num.24-2020-2677 